\title{
Theories of Nomadic Movement: A New Theoretical Approach for Understanding the Movement Decisions of Nenets and Komi Reindeer Herders
}

\author{
M. J. Dwyer • K. V. Istomin
}

Published online: 11 June 2008

(C) The Author(s) 2008

\begin{abstract}
It is known that the relationship between humans and their animals is important for understanding many aspects of nomadic pastoralist systems, including nomadic movement. However, to date, these complex human-animal relations have not been analyzed in a way that has led to an explanatory model of nomadic movement capable of producing testable hypotheses. Based on ethnographic material collected amongst Komi and Nenets nomadic reindeer herders of the Russian Arctic, we argue that nomadic movements can be best understood as a product of the interplay that exists between animal behaviour and the herders' skilful actions to (a) maintain herd cohesion and (b) avoid hazards, whilst deploying the minimum amount of resources (i.e., human/animal effort and use of equipment) on rounding up the herd, stopping and turning it. Ecological factors affect movement through their influence on animal behaviour, whereas non-ecological factors do so by influencing the herders' skilful actions. We demonstrate that, based on these assumptions, it is possible to build a testable model explaining the movement of some nomadic groups.
\end{abstract}

\footnotetext{
M. J. Dwyer $(\bowtie)$

Department of Geography, University of Cambridge,

Downing Place,

Cambridge CB2 3EN, UK

e-mail: m.j.dwyer.00@cantab.net
}

\section{K. V. Istomin}

Max Planck Institute for Social Anthropology,

Advokatenweg 36,

06114 Halle/Saale, Germany

e-mail: Istomin@eth.mpg.de
Keywords Komi · Nenets · Nomadism · Movement · Reindeer herding

\section{Statement of the Problem}

Movement of both animals and people is an inherent aspect of nomadic pastoralism and research into why and how movement takes place has formed a substantial part of anthropological studies of nomadism (see Irons and DysonHudson 1972; Dyson-Hudson and Dyson-Hudson 1980; Salzman 2003, 2004). Although many of these showed that nomadic pastoralist movements, including migration patterns, were influenced by a number of biotic and abiotic factors (see Dyson-Hudson and Dyson-Hudson 1980 for a review), it appears that no model - be it general or specific - has been formulated to explain how various types of factors interact to produce a particular type of movement. In fact, it was claimed that a general explanatory model of nomadic pastoralist movements would be impossible to build, since nomadic pastoralism did not represent a "coherent phenomenon" (Dyson-Hudson and Dyson-Hudson 1980:51-56) ${ }^{1}$.

We believe, however, that local or regional scale analytical models of nomadic pastoralist movement would be possible if a more general approach, expanding on existing research, was employed. This paper, therefore, aims to identify and evaluate the shortcomings of previous approaches to nomadic movement. In so doing, the ways in which these approaches can be combined and improved are explored using the case study of arctic reindeer herders, and

\footnotetext{
${ }^{1}$ In fact it was argued that the very concept of nomadic pastoralism should be abandoned for this reason (Dyson-Hudson and DysonHudson 1980: 55-56).
} 
a refined model that explains their movements is subsequently presented. Three steps are taken to achieve this aim: firstly, previous approaches to building explanatory models for nomadic movement are reviewed and ways of improving them are suggested; secondly, ethnographic material collected amongst the Komi and Nenets nomadic reindeer herders is presented; thirdly, a new analytical model is proposed based on steps one and two - which enlarges on the previous explanations - and its applicability to other nomadic groups is discussed.

\section{Methodology}

Ethnographic data were collected during fieldwork conducted by both authors in the Inta region of the Komi Republic and the Nenets Autonomous Okrug (northeastern part of the European Russian Federation) as well as in the Yamalo-Nenets Autonomous Okrug (northwestern Siberia) see Fig. 1.

Three expeditions took place amongst the Komi reindeer herders of Sovkhoz (reindeer herding enterprise) Bol'shaya
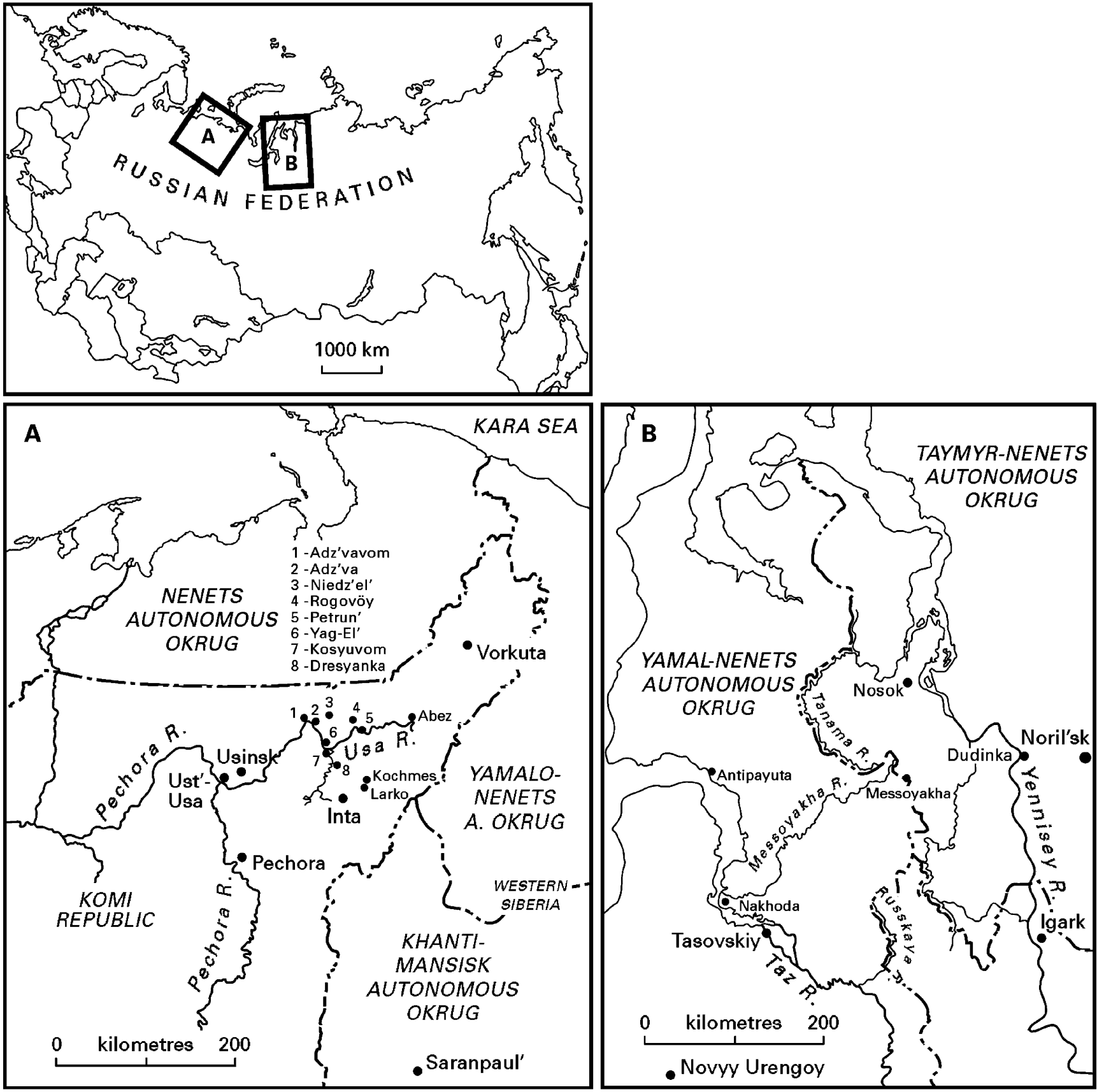

Fig. 1 Map locator 
Inta, who migrate mostly in the Nenets Autonomous Okrug: 2001 (September-November); 2002 (June-December); 2003 (January-February). A total of 12 months was spent migrating with the herders throughout these periods. Between August 2001 and February 2003, over 6 weeks was spent interviewing retired reindeer herders in small remote villages: The Nenets herders in the village of Kharuta (3 days); The Komi herders in the villages of Adz'vavom (2 weeks), Kosyuvom (1 week), Petrun' (3 weeks), and Rogovoy (3 days). A further three expeditions were carried out during autumn-winter 2005, summer 2006, and spring 2007 in the region of the River Taz - the southern part of the Gydan Peninsula which, administratively, represents the Tazovsky district, Yamalo-Nenets Autonomous Okrug which focused on the Taz group of Nenets reindeer herders. During these expeditions, around 4 weeks were spent interviewing retired reindeer herders in the village of Tazovsky (October-November, 2005) and 7 months migrating with herders of the Tazovsky Sovkhoz. The research included participant observation together with interviews conducted in the Komi and Russian languages. The interviews were informal and no specially designed questionnaires were used. Komi and Nenets terms were translated into Russian and English for the purpose of analysis and the interviewing process was repeated several times with different individuals and groups of herders in order to cross-reference data.

\section{Review of Anthropological Explanations of Nomadic Pastoralist Movements}

Possibly the oldest, most obvious and most ubiquitous explanation of nomadic pastoralist movement in popular literature is that nomads move to new pastures to find fodder and water for their herds. Explicitly worded in the 16th century by Rashid Al-Din, this explanation dominated nomadic studies in both geography (e.g., Semple 1933; Forde 1934) and anthropology (e.g., Evans-Pritchard 1940; Myers 1941) up until the late 1960s. It was not, however, until the beginning of the 1950s that anthropologists became interested in constructing more detailed explanatory models based on this general explanation (Dyson-Hudson 1972: $6^{2}$ see also Dyson-Hudson and Dyson-Hudson 1980; McCabe 1994).

By the 1960s, two basic modelling approaches had crystallized (see Paine 1972:77). The first one utilised the notion of the existence of homeostatic relations between nomadic pastoralists and their environment and viewed

\footnotetext{
${ }^{2} \mathrm{He}$ mentions that some attempts were undertaken just before World War II (e.g., Evans-Pritchard 1940; Lattimore 1940), but it was not until the 1950s that these works were heeded by the scientific community.
}

mobility as a basic mechanism for maintaining this homeostasis by levelling the fluctuations (seasonal, etc.) in the supply of resources (mainly fodder and water) in any particular place (e.g., Barth 1961). The second approach attributed by Paine $(1972,1994: 14)$ to Evans-Pritchard (1940) - denied the homeostatic relation between pastoralists and their environment. Instead, nomadic movements served to maximize the supply of resources, which could vary rather significantly from season to season, for the herds at any particular moment of time.

However, it also became evident in the 1950s-1960s, that animal resources (fodder and/or water) were not the only factor influencing nomadic movements; there were also a number of other biological factors (e.g., tsetse flyStenning 1958, 1959) as well as nonbiological factors including economic and social relations with other groups (nomadic and settled), national governments, and social relations between individuals within a nomadic group (Lattimore 1940; Stenning 1958; Barth 1960, 1961; Bates 1972, 1973 to name just a few from this period). Although resource (ecological) factors were generally regarded as being the main consideration until the end of the $1960 \mathrm{~s}$ (McCabe 1994:72), the urge to incorporate further factors into explanatory models was observed. According to Gulliver (1975), pastoral nomads obviously moved in response to ecological (resource) factors, however, the manner in which they did so left open many "opportunities of roughly equal pastoral advantage" (1975:372). In other words, pastoralists had "a degree of freedom of action" where sociocultural considerations could (when ecological conditions were more or less equivalent) determine their course of movement (1975:372-373). An essentially similar approach was proposed by Neville Dyson-Hudson (1972). For adherents of these models, ecological and nonecological factors affected movement on different scales of precision: ecological factors determined the general features of the migration patterns (such as seasonal migrations from one ecological zone to another), while non-ecological factors determined the concrete details of movements and schedules.

However, these models attracted severe criticism in the 1970s (see Bates 1973; Irons 1974; Burnham 1975; Elam 1979). Ecological studies demonstrated that the relation between nomadic pastoralists and their environment could generally not be viewed as being homeostatic and thus the theories of Barth (1961) and Spooner (1972), which had been based on this premise, were undermined. The anthropological studies showed that in certain nomadic pastoralist systems (see Irons 1974; Elam 1979) there were no ecological reasons for nomadic migrations; these nomads moved exclusively for political, economic or social reasons, which suggested that both ecological and nonecological factors could be of equal importance in causing 
and shaping nomadic pastoralist movement, and that this movement could be caused and shaped by all or any of them (Dyson-Hudson and Dyson-Hudson 1980). Consequently, the very concept of nomadic pastoralism was also being questioned (Dyson-Hudson and Dyson-Hudson 1980)

In the second half of the $1980 \mathrm{~s}$, a new stage of anthropological research took place, primarily undertaken by the well-known Turkana project researchers (see Little and Leslie 1999). This new research was marked by applying what Orlove (1980) named a 'process-approach' using 'actor-based models' as opposed to the previous 'pattern-oriented approach.' Generally, this meant a change of research agenda that now focused on the factors and processes involved in shaping the individual behaviour of an actor, most often represented in the form of decisionmaking models, rather than on explaining abstract patterns, such as those of migration (Orlove 1980:246). As a result, explanatory models of movement began to be perceived as those explaining movement decisions and two approaches in model building crystallized. One focused on the factors influencing these decisions, which left the actual process of decision-making outside the scope of its analysis ("microeconomic models" Orlove 1980:246-247). Early anthropological publications of the Turkana Project (e.g., Dyson-Hudson and McCabe 1985; McCabe 1994) which calculated the relative numbers of 'migratory' decisions made for ecological, economic, social, and political factors to understand their relative influence on nomadic pastoralists' movement, serve as a good example. Many studies of this kind (e.g., De Boer and Prins 1989; Sieff 1997; Robbins 1998; Turner 1999; Coppolillo 2000; Schareika 2001; Adriansen and Nielsen 2002) belonged to different branches of Human Environmental Ecology (sociobiology) (see Cronk 2000). Some of them used models developed in animal ecology, i.e., the optimal foraging model (e.g., De Boer and Prins 1989), whereas others (e.g., Sieff 1997) used dynamic optimality models to explain and predict movement choices (by maximizing certain 'proxy currencies' $^{3}$ (see Mulder and Sellen 1994)). Outside of Human Behavioural Ecology, microeconomic models were exemplified by the economic defendability model, first applied in anthropology by Dyson-Hudson and Smith (1978), and further developed in Casimir's (1992) study of land property rights which was partly based on the biological optimality matrix.

\footnotetext{
${ }^{3}$ Mulder and Sellen (1994) define this term as: "The currency can be any outcome, such as maximization, minimization or variance reduction in a commodity such as food, herd size, labor or productivity. Currencies are only proxy measures of fitness, but must be proven to have (or likely to have) some effect on ultimate evolutionary fitness" (1994:206).
}

The second approach focused on the actual process of decision making with a view to building up its cognitive models (Orlove 1980: 246-247). Some studies using this approach were also Human Environmental Ecology related (e.g., Schareika 2001; see also Erdenebaatar 1996) and endeavoured to explain the decision-making process by formulating a set of decision rules, supposedly transmitted from one generation to the next through the process of enculturation. The theoretical assumptions upon which these attempts were built have recently been criticized (see Ingold 1990, 1996, 2000). Other studies, which were much more numerous (e.g., McCabe 1994; Beach 1990), were related to more traditional branches of anthropology.

Neither approach has resulted in a coherent explanatory model for nomadic pastoralists' decision making in relation to movement. This is probably because both approaches have significant shortcomings. Although the microeconomic models - based on optimality theory - can generate testable hypotheses regarding which factors influence nomadic movement, their abstraction from the decisionmaking process seriously hinder their ability to explain exactly how these factors work together to produce specific decisions. As theorists of the optimality models themselves accept (e.g., Smith 1983), these models do not explain how movement decisions are actually made, let alone predict them in detail. They would be better viewed as either shortcuts or credible guides to developing such an explanation. Furthermore, even the function of optimality models in relation to nomadic movement is often ambiguous since most models do not base their analysis on the supposed decision-making agents per se, but rather on the nomadic pastoralist system in general treated as a single black box. This approach, in simplified form, is graphically represented by Fig. 2 .

This approach may have been adequate if a single locus of decision making existed in a nomadic pastoralist system (represented, for example, by nomadic herders) capable of producing decisions that optimized the influence of the factors, and if the resulting movement depended exclusively on the decisions made in this locus. However, as studies

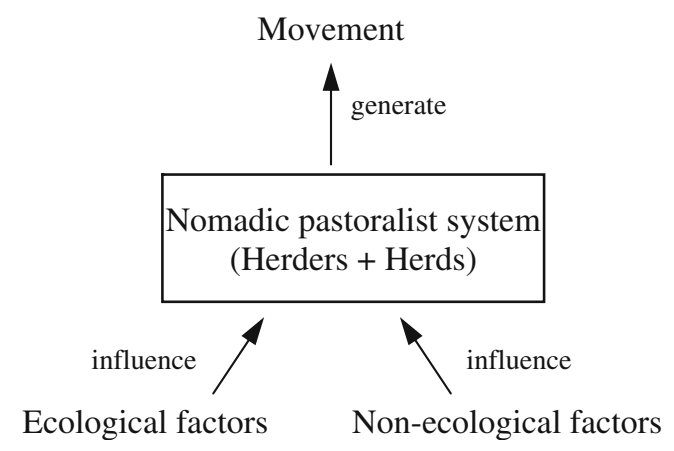

Fig. 2 The approach for applying optimality models to nomadic pastoral movements 
representing the second approach (cognitive models) clearly signify, both these assumptions would be wrong. A nomadic pastoralist system is not a coherent unit. It consists of at least two basic elements - humans and animals - between which interrelations are rather complicated and need to be taken into consideration in any theoretical generalization:

Understanding a pastoral society involves understanding its herding operations. Understanding the herding operation in turn involves understanding the species herded. In short, for pastoral societies "social significant phenomena" comprise a far wider category than "social phenomena", and the present unsatisfactory state of nomadic studies must in part be attributed to the slowness with which social anthropologists have come to terms with the results of veterinary and pasture research (Dyson-Hudson 1972:14).

In fact there are a number of pointers in existing literature that indicate that nomadic movements result not only from decisions taken by the herders, but also from the behaviour of animals over which herders have little influence. For example, Erdenebaatar (1996) mentioned that the Mongol nomads were forced to make very frequent movements between seasonal pastures because the animals tried to return to abandoned pastures and that frequent movement was the only way to deter them from doing so. Similarly, Turner (1999) mentioned that cows became quite 'picky' over grass species during some periods and were, therefore, calmer in more diverse pastures. Furthermore, Coppolillo (2000) noted that larger herds of cows tended to walk further distances than those that were smaller ("...ten steps without a bite") and thus moved faster (2000:555). He also presumed that this could explain why larger herds had longer migration routes than those of smaller herds, and also why nomads tended to divide their herds.

A number of accounts of this kind can be found in literature on reindeer herding nomads. For example, in the second half of 19th century, Maksimov (1868) argued that rather than pasturing reindeer the Nenets herders followed them. However, even the extreme idea that there is a single locus of movement decision-making, which, however, rests with animal behaviour is strongly opposed by some scholars (see Beach 1990; Ingold 1988 [1980], 1986). For example, Beach (1990) states that:

"Although the nomad's common explanation of his own movements is 'the reindeer decide', this is a truth with modification. There is great flexibility in the decisions that the reindeer can adopt as customary and the reindeer nomad greatly assists in helping the reindeer make up their minds... In effect the reindeer come to decide what the herder (within bounds) has decided for them" (1990: 269-270).
In other words, the herders "know the possible range of behaviour of the reindeer under different climatic conditions", "predict reindeer behaviour during the shifting interplay of climate, grazing and landscape" and "adapt herding to these conditions" (Beach 1990:268). Paine (1994) put essentially the same idea in even stronger terms arguing that "reindeer pastoralism rests upon the successful deciphering of herd behavior by herders" (1994: 31).

This suggests that existent complex human-animal relations should be considered in order to understand the herders' actions/decisions with respect to movement. On the other hand cognitive models, although emphasizing the role of these relations, are inadequate in providing either a theoretical argument or testable hypotheses on how various external factors influence nomadic movement. Therefore, a general explanatory model of nomadic pastoralist movement could seemingly be achieved only by building upon a combination of elements of microeconomic and cognitive actor based models.

\section{Movement and Reindeer Pasturing Technology: The Cases of the Izhma Komi and the Taz Nenets}

\section{The Izhma Komi}

The Izhma Komi reindeer herders of the Bol'shezemel'skaya Tundra (henceforth referred to as Komi herders) live in teams usually consisting of six to eight males and several females. All the members of a team cohabit in one nomadic conical shaped tent (chom in Komi) and are normally related to each other by blood or marriage. These teams (brigada $^{4}$ ) each pasture from 2,000 to 4,000 reindeer; the larger proportion of these animals is the property of reindeer herding enterprises (former sovkhozes ${ }^{5}$ ), and the remainder belong to the reindeer herders themselves. The animals controlled by each brigada are divided into two herds: one consists of castrated male reindeer used for transportation $(b y k)$, and the other incorporates female and non-castrated male reindeer as well as calves $(k \ddot{o r})$. The byk

\footnotetext{
${ }^{4}$ The Russian term usually used to designate a work unit in a socialist state enterprise. However, historical sources show that both the social organization and the technology of Komi reindeer herding described here existed long before the establishment of socialist reindeer herding enterprises (Kercelli 1911; Babushkin 1930).

${ }^{5}$ Sovkhoz (sovetskoye khozaystvo - meaning Soviet enterprise): Stateowned agricultural enterprise (in this case reindeer herding) in the north of the Soviet Union and in Siberia after the 1960s - beginning of the 1970s. After the collapse of the Soviet Union, nearly all sovkhozes were privatized and turned into agricultural cooperatives (without state control) or share-stock companies. This, however, had little impact on their structure and methods of work (see Konstantinov 2004) and, in the Komi Republic, the state recently had to buy many of them back in order to save them from bankruptcy.
} 
herd, usually numbering between two and four hundred animals, is always pastured in close proximity to the tent so that the nomads always have a means of transport at their disposal. The $k \ddot{o r}$, which includes $80-90 \%$ of the total number of animals, can be as far away as $10-15 \mathrm{~km}$ from the camp. In spring and summer, each herd is permanently observed and controlled by one reindeer herder (working a $24 \mathrm{~h}$ shift) with a reindeer sledge and between two and four herding dogs. In autumn and winter, when the long dark nights make $24 \mathrm{~h}$ observation impossible, control over the animals is loosened. The herds are, nevertheless, visited and rounded up every day.

The migration pattern of Komi herders is linear and meridian: each year, a brigada completes a return journey from the forest-tundra zone in the south through to the tundra zone on the coast of the Barents and Kara seas in the north. This migration follows an established path called vörga. Two brigadas generally share the same path (although they do not camp together except when near the sea coast in the summer) and pasture their reindeer on different sides of it. Considering that vörgas run parallel to one other from south to north - the distance between two neighbouring paths ranging from between two and $12 \mathrm{~km}$ at any given location - a pasturing corridor typically has to be shared by two brigadas (see Dwyer and Istomin 2006). The current length of the paths can reach at least $450-500 \mathrm{~km}$, so that the Komi travel up to $1,000 \mathrm{~km}$ per year; there is evidence that this figure was considerably larger in the recent past (Dwyer and Istomin 2008). Along the vörgas, established camping sites (chom mesta) are situated at a distance of 10-13 km from one another; this distance is known as lunkost (daytrip), and the brigadas' migration usually consists of moving from one camp site to the next.

The Komi herders showed that their movements heavily depended on the movement of the larger kör herd and asserted that it should always be behind the camp (e.g., to the south of it when migrating northwards), since when the animals graze they gradually move towards the camp. Once the kör herd is close to the camp, the herders move to the next camp site and the distance between the camp and the $k \ddot{o r}$ is re-established ${ }^{6}$. The movement of the $k \ddot{o r}$, therefore, appeared to be the key factor determining the movements of the herders and should be discussed in some detail.

As mentioned, both the kör and the byk herds are observed constantly in spring-summer, or during the days in winter, by duty herders with sledges and several dogs. It

\footnotetext{
${ }^{6}$ Some exceptions to this general model were observed. For example, if the herd reached the camp in the evening or in the middle of night, most brigadas did not start to migrate immediately and allowed the herd to temporally go in front of the camp until they could move the following morning.
}

transpired that a duty herder has three basic tasks: a) to keep the herd coherent and prevent it from dispersing and separating into smaller groups of reindeer (palakh), some of which can easily slip from under the herder's control; b) to protect the herd from environmental hazards, such as predators and dangerous terrain ${ }^{7}$; c) to avoid his herd mixing with those of other brigadas. His failure to perform these tasks will inevitably result in the loss of reindeer. Study of the actual herding process showed that performing these tasks depends firstly on the ability of the herder to perceive and react to the herd's behaviour. The herders reported a number of factors influencing this behaviour, such as quality, quantity and accessibility of fodder, air temperature, mosquitoes, micro-landscape, ground humidity, etc. For example, low quantity and/or insufficient quality of fodder tends to cause the herd to disperse; harassment by mosquitoes forces reindeer to group together and move with greater speed against the wind; reindeer move more slowly when temperature is low, etc $^{8}$. The responsive strategies of a duty herder to these different kinds of reindeer behaviour could be grouped into two types: Firstly, the herder can influence the behaviour of the herd directly by travelling around it on his sledge with or without his herding dogs to round up the dispersed herd again; to return a group of reindeer that have become separated from the herd; or to redirect a herd moving too fast or in the wrong direction (towards a dangerous terrain or in the direction of another herd) due to mosquitoes. Secondly, the herder can attempt to change reindeer behaviour by moving with the herd to a new location. Thus, if a herd tends to disperse in a particular place (e.g., as a result of intensive pasturing in one location), one solution can be to move to another place which has more vegetation or vegetation of a different kind; if the herd moves too fast (in the case of intense heat or mosquitoes), it can be moved to a windier or cooler place, etc. In addition, the factors influencing reindeer behaviour can be balanced against one another through movement. For example, taking the herd to a place rich in fodder can decrease the speed of its movement (and make the tasks of a duty herder easier to perform) even on a warm mosquito-ridden day. Moving the herd (or allowing it to move itself) to a new place is also the most efficient way to avoid dangerous terrain as well as to decrease the risk of herd mixing. It should be noted, however, that these manoeuvres with the

\footnotetext{
${ }^{7}$ Dangerous terrain includes steep slopes, deep streams and bogs where reindeer can fall or drown. It also includes a thermokarst called tabey in Komi, which occurs as a result of an accumulation of wet mud under a thin layer of soil due to the melting of permafrost. When reindeer cross tabey they can easily sink into the soil and die.

${ }^{8}$ Many of these statements correspond to the findings of reindeer ethologists (e.g., Baskin 1970; Skogland 1989, 1991).
} 
herd are rather restricted in space: the duty herder cannot approach the neighbouring migration paths with his herd and cannot cross his own vörga in the case where it is used by two brigadas. In fact, this manoeuvring is always directed roughly towards the camp, since the land in the opposite direction (from where the herd had just come) would already have been used and moving back would increase the risk of herd dispersal.

It was observed that all Komi herders used both types of pasturing strategies. However, touching (vörz'ödny) [interfering with] the herd too often to round it up, stop it or change its direction is inadvisable, as this disturbs the process of reindeer grazing and exhausts the duty herders' draft reindeer and dogs. On the other hand, a lack of herding intervention can result in the herd approaching the campsite too quickly forcing the brigada to move to the next encampment. Moreover, too frequent movements are not always in the interests of the herders, since they exhaust the draft reindeer and leave too little time for important subsistence activities, such as processing hides, sewing clothes, sledge building and repairing, fishing, etc. In short, the real art of reindeer herding primarily consists of accomplishing the herding tasks (i.e., keeping the herd coherent, protecting it, and avoiding mixing with others) with both minimal direct influence on the herd using a sledge and dogs, and the minimal exploitation of the territory between the herd and the camp in the process of manoeuvring; thoughtful observation and evaluation of reindeer behaviour and balanced application of both direct influence on the herd and spatial manoeuvring can achieve this.

\section{The Taz Nenets}

A Taz Nenets (henceforth named Nenets) herding camp consists of four to seven families, each living in its own tent. In contrast to the long linear and meridian migration pattern of the Komi, the Nenets move in a circular pattern within a given territory ${ }^{9}$, but without any established migration route. Each camp manages a reindeer herd numbering from 1,500 to 3,500 animals, not divided into groups, but pastured as a coherent whole and left to graze unobserved most of the time. The only exception is the calving period (end of April to the end of May), when pregnant and newly calved female reindeer (yahadey) together with their newborn calves are pastured separately from the rest of the herd (ty). The herds are rounded up once a day in winter or twice in spring and autumn and driven to the campsite to check whether all animals are present; choose new animals for harnessing; slaughter some for food and hides, and allow state-sponsored zootekhniks

\footnotetext{
${ }^{9}$ Each camp has a rectangular shaped territory of around $60 \mathrm{sq} \mathrm{km}$.
}

(veterinaries) to treat any sick reindeer. Finding and rounding up the herd typically involves a joint effort of two herders in winter and four in spring and autumn, each with a reindeer sledge and team of two to four herding dogs. Knowledge of typical reindeer behaviour is used to find the animals, which have usually dispersed into several separate groups by the time rounding up occurs ${ }^{10}$. The periods of calving and mosquito abundance (end of June to the beginning of August) represent exceptions to this model: the yahadey herd during the former period and the entire herd during the latter are observed permanently by two duty herders working on a 24-h-shift basis. The manner in which this observation is performed, however, differs from that of the Komi. For example, in the calving period, the herders are very careful not to influence the calving herd in any way, as this can scare the pregnant females about to give birth and increase their risk of miscarriage. They simply observe the slow-moving females and return any that try to disperse (usually those that have still not given birth). In contrast to the Komi who do not separate pregnant females into a separate herd, the main activity in the calving period consists of keeping the productive herd in one place by preventing the younger animals and males from leading it farther towards the north.

The main factor triggering the Nenets' movements was when the herd was difficult to find and round up at a particular camp. The herders stated that they often had to move because the reindeer that had been released from the campsite could quickly become dispersed and wander too far away from the camp by the time of the next rounding up. Therefore finding them and driving them back to the camp became time-consuming and demanding for the herders' draft reindeer and dogs, and the risk of losing track of some smaller groups of reindeer increased. This reindeer behaviour was provoked by the deterioration of fodder (in quantity and/or quality) near the camp and movement to a new location was therefore required. Considering that a new campsite should have a large area of fresh pastures, the longer the herders stay in one place the longer their subsequent move has to be ${ }^{11}$. Similarly to the Komi, Nenets herders, despite their knowing that reindeer behaviour is influenced by the quality/quantity of

\footnotetext{
${ }^{10}$ For example, the herders say that reindeer usually walk against the wind, along streams and natural depressions, and tend not to return to pastures that have been trampled or grazed (see Baskin 1970). Therefore, by remembering the wind direction (for orientation purposes) and knowing the landscape and where reindeer were previously found, it is possible to determine their location.

${ }^{11}$ During the calving period the herders try to move as little as possible, since it is arduous for newborn calves to follow the brigada to new camps. This means that by the end of the calving period, the herd of calves and females is usually $15-20 \mathrm{~km}$ away from the brigada, since several camp changes would have taken place to enable the herd of male reindeer to be successfully pastured.
} 
fodder, made their movement decisions in relation to reindeer behaviour per se, rather than any assessment of fodder.

Taking into account that the pattern of Nenets migrations is circular with no established migration routes, it is important to understand how they select the direction of their migrations. It emerged that two basic models of migration exist. The first - which can be called the 'double loop' - consists of two circles of migration: the winter circle (from November to the beginning of June), made in the forest and/or forest-tundra zone and the summer circle (from June to November), made in the tundra. The circles are connected at one point, situated not far away from the tree line, where the herders leave their winter equipment (e.g., winter tents covered by reindeer hides and warm winter clothes) in June and pick it up in late autumn (November). The second model of migration consists of three circles: winter - from November to the beginning of June; spring/summer - from June to August; summer/ autumn - from August to the beginning of November. These circles are also connected at the equipment storage place. In this model, the winter circle is also made in the forest/forest-tundra, the spring/summer circle is performed along watersheds, covered by willow stands (neros' $a$ and payu) and the summer/autumn circle is made in the open tundra (lapta). The herders return to the winter equipment storage place twice - once in summer (usually in the middle of August) and once in late autumn - which allows them to reduce the number of items they carry during their movements. Concrete locations in which the migration circles are made change every year: the same territory should not normally be used throughout two consecutive years, since lichen ( $n$ 'ado in Nenets) grows very slowly. This does not apply to the land along watersheds used in the middle of summer. As the herders put it: "reindeer do not need lichen in summer, as grass and leaves grow back every year."

The migration route is determined in spring and is mainly related to where the equipment storage place is located. If it is situated between the watershed and the area of open tundra, on land which has not been in use for some time (a minimum of 2 years), the three-circle model is chosen. The herders consider this to be the most appropriate, since it greatly decreases the burden of draft animals. It is, however, not always possible to perform, since the open tundra areas in proximity to the watershed may already have been used during previous years. In this case, the double loop model is opted for, in which the herders go to the open tundra across the watershed and return back in late autumn performing only one summer circle.

The explanations herders gave for these migration patterns were sometimes contradictory and, probably, simplistic. What is important, however, is that these explanations more often than not referred to expected reindeer behaviour in a particular territory and the workload needed to cope with it. Thus, the herders explained that making the winter circle in the forest/forest-tundra zone is mainly due to its softer snow cover, which makes it easier for reindeer to dig out the lichen and, in turn, means a more cohesive herd and a decrease in herd dispersal (the other popular explanation was that good availability of firewood can be found there). Similarly, in the first half of summer, willow stands are used to decrease the speed of herd movement, since they provide cooler pastures and thus some relief from mosquitoes, and make dealing with the herd easier. Herders who attempted to pasture reindeer in the open tundra during the mosquito period often lost their herd because their draft animals became tired of the heat, mosquitoes, and permanent workload. Similarly, moving into the open tundra after the mosquito period is explained by the herders for two reasons: firstly, dispersed groups of reindeer are easier to find and round up in the open tundra than in the forest and willow stand; secondly, there are fewer mushrooms in the open tundra compared to the forest or willow stands; reindeer are fond of mushrooms (which start to grow in the tundra in August) and disperse extensively in search of them.

As can be seen from this description, choice of a migration pattern indeed involves some simple ecological considerations on the part of the Nenets herders, particularly the tendency to avoid a grazed territory for several years in order to allow it to recover. However, it would appear that the main factors influencing choice of distance, direction, and length of time of their movements are (a) the need to cope with and react to reindeer behaviour; (b) to do this in such a way as to retain control over the animals with reasonable disposal of resources - including time - and human, draft reindeer and dog power. In this respect, the technology of Nenets herders is strikingly similar to that of the Komi. The main distinction is that Komi endeavour to control their animals constantly, whilst the Nenets, for most of the time, take control of the reindeer and release them regularly. This distinction, however, in relation to our research seems to be rather in form than in principle.

\section{Reindeer Behaviour and Herding Technology}

The short description of Komi and Nenets pasturing technologies and patterns of movement decisions confirms the observations of Beach (1990) and Paine (1994) that the ability of herders to forecast, interpret and react skillfully towards the behaviour of reindeer is the central element of reindeer herding. As is the case amongst the Saami, for the Nenets and Komi, "reindeer pastoralism rests on successful deciphering of herd behavior by the herders" (Paine 1994: 31). Paine mentions, however, that this deciphering and reaction in reindeer herding is actually a two-way process 
- a phenomenon which he names 'reciprocal learning': "Animals learn about their herders' order of things, as well as herders about their animals." (1994:31).

The comparison of observations made among Komi and Nenets reindeer herders confirm that reciprocal learning such as this indeed takes place. It was observed that reindeer from Nenets herds, if not found by the herders during the course of the daily round-up, tended to return to the campsite of their own accord after some time. The herders reported that these reindeer tended to return to the same campsite that they were driven to by the herders during the previous round-up. When the herd is rounded up and moved to a new campsite, those animals that are missing will most likely return to the previous campsite. It was also reported that this behaviour depended on the number of times the animals had been driven to a particular campsite. For example, if the animals were 'lost' immediately after movement to a new place or if they were rounded up and driven to this place only once or twice, they would likely return to the previous campsite. In addition, stray animals tended to return to the campsite if either attacked by predators or harassed by mosquitoes.

It was observed that Nenets herders relied heavily on this behaviour. For example, in spring and early autumn, when the pasture conditions were good and reindeer did not wander far away from the camp for long periods of time, the herders tended to accept the much larger dispersal of the herd before moving on to a new place than in summer and winter. Their explanation was that reindeer had 'learnt' to return to this particular place for long enough and, therefore, the danger of losing them was low despite difficulties finding and rounding them up every day: the animals that the duty herders failed to find were likely to return to the camp by themselves. In one particular case (June, 2006) it was observed that after a 22-day period in one place, the herd became so dispersed that the duty herders only managed to round up around $1 / 3$ every day. The brigada did not move, however, since the herders expected all the reindeer to return to the campsite of their own accord when harassed by mosquitoes at the start of the biting insect season. This expectation turned out to be justified.

On the other hand, the Komi herders' reindeer could not return to a campsite of their own accord. Consequently, a herd needed to be observed constantly. Apparently the contrast between the two groups is due to reciprocal learning. For example, the return to a campsite, by the Nenets reindeer must have been the product of their instinct (i.e., the tendency to rejoin the herd) modified by their experience with a particular herding technology (i.e., the campsite is the focal point where other animals are most likely to be met). However, Komi reindeer herding technology does not create such focal points and, Komi reindeer do not demonstrate the same behavioural pattern. This example is unlikely to be unique. The older Komi herders described the problems they had with reindeer that were bought for them in the Yamal Peninsula at the end of the 1950s, when they experienced huge losses due to footand-mouth disease. They described the new animals as being 'wild', and that they soon became lost.

These findings suggest that animal behaviour can partly be the product of a particular herding technology, which reaffirms the idea put forward in many anthropological works that an animal herd is not only a biological but a social phenomenon.

\section{New Proposed Model of Pastoralist Movement}

\section{The Concept of Herd Control}

The ethnographic material presented in this paper confirms that reindeer herders' movements are the direct result of a relationship that exists between herders and their reindeer, whereby the actions of the herders depend largely upon the behaviour of the herd. Consequently, to develop an explanatory model of reindeer herding movement, focus should be placed on this relationship. 'Herd control' comprises ensuring the herd's cohesion and manageability, its protection from predators and dangerous terrain, and prevention from mixing with other herds. As demonstrated, 'herd control' can be regarded at best as a product of the interplay, including reciprocal learning, between reindeer behaviour and the actions of the herders. During the process of this interplay, reindeer behaviour can be modified by the herders' actions, but by no means determined by them. Importantly, in their dealings with the animals, the herders, understandably, aim to act in such a way that expenditure related to their actions, in terms of time, labour, and draft reindeer and dog power, are kept to a minimum. Hence, herd control can be best understood as a result of herders' attuning their actions to reindeer behaviour that has been partly produced by these very actions. There appear to be various ways of achieving this; e.g., permanent observation of the animals, regular rounding up, and leaving them to graze freely most of the time.

Ecological factors influence reindeer herding movement through their impact on reindeer behaviour, which is very sensitive to even the slightest change to the environment. Thus, when making movement decisions, the herders, rather than constantly assessing an incalculable number of environmental factors and moving accordingly, generally attune their actions to environmental variability by responding to changes in reindeer behaviour alone. For example, the amount and quality of fodder is one of the basic factors influencing reindeer herding movement. However, from a 
reindeer herder's point of view, movement is not determined by whether or not a pasture has become 'exhausted'; rather movement is made according to (albeit not solely) the degree of effort that is required by the herders ${ }^{12}$ to keep his animals under control on this pasture. The herders move when reindeer no longer want to stay on the pasture. The abundance of forage (i.e., a biotic factor) influences the 'willingness' of reindeer to stay on the pasture: the less abundant the forage, the more willing the reindeer are to move. However, the herders react to the behaviour of reindeer rather than to the abundance of forage.

So far, we have discussed only how the reindeer herders' movements are influenced by the ecological requirements of the reindeer. However, the requirements of the reindeer herders themselves are also important determinants of reindeer herding movements and reflect mainly the nonecological factors influencing them. Firstly, reindeer herders need to exploit the resources that are available in the natural environment (e.g., wood and bark for fuel, water, fish, game and wood for making objects). The abundance and availability of these resources, of course, vary temporally and spatially. Secondly, the herders' need to trade with the settled population, as well as other nomads, which is possible only in certain places. Thirdly, they need to make/repair material objects, such as sledges, tent poles, etc., which demands staying in one place for some time. Fourthly, they need to meet up with the transport (e.g., helicopters) that is irregularly sent to them in order to bring supplies, pick up reindeer meat, provide medical care, give lifts to nomads going to villages, etc. Fifthly, they have broader social needs (e.g., relaxing in a warm flat, watching television and seeking companionship), which are available mainly in villages. The social setting and political and economic agencies also influence nomadic movement: the reindeer herding enterprises can order the herders to bring their herds to special corrals in order to count the animals, to choose reindeer for slaughter, to give the reindeer injections, etc., as well as to bring the chosen animals to a slaughter house. The traditional system of land tenure binds Komi herders to established migration routes (vörga), and Nenets herders to defined, although changeable land plots $(y a)$; the state can remove a patch of territory from the agricultural allocation (vyvesti iz selskohozajstvennogo oborota), i.e., confiscate it from the herders and give it, for example, to an oil or gas drilling company (see Habeck 2005).

These factors influence herders' movement decisions in ways that would often have been different if they had been made exclusively to maintain control over the herd with minimal disposal of resources. These differences, however, always increase the risk of loosing control over the herd,

\footnotetext{
${ }^{12}$ This also includes the level of effort required by the herders' transport reindeer and dogs.
}

which can be partly mitigated through an increase in workload (in terms of human, reindeer and dog power). It is argued, therefore, that the herders' actual process of movement decisions involve constantly assessing and balancing the risk of losing control over the animals and the increase in the workload needed to mitigate it on the one hand and the need to satisfy the herders' needs and respond to non-ecological factors on the other. It transpired that the need to maintain herd control usually took precedence, i.e., the herders deviated from the optimal pattern of movement for controlling the herd only when the risk of losing its control could be mitigated by a reasonable price in terms of increased workload. To illustrate this point, on one occasion the Nenets were ordered by the sovkhoz to repair a damaged corral. However, to do this, the camp had to pasture its reindeer in an area deemed unsuitable. This caused the herd to disperse over a wide area and the combined effort of as many as eight of the 11 herders present in the camp was required every day to retrieve all the groups of reindeer and bring them to the camp; this made the repair work very slow. Eventually the repair work was abandoned, as avoiding a conflict with the enterprise over uncompleted work did not warrant the potential loss of reindeer, which would have been expected had the camp stayed near the corral.

\section{New Proposed Model}

Figure 3 shows that reindeer herding movements amongst Komi and Nenets reindeer herders result from the interplay between reindeer behaviour and the actions of the reindeer herders aimed at achieving 'herd control' - which includes herd cohesion, manageability and safety - with minimum costs in terms of human and animal power. This interplay involves the herders' perception of reindeer behaviour and their reaction to it. The interplay is influenced, on the one hand, by the impact of ecological factors on reindeer

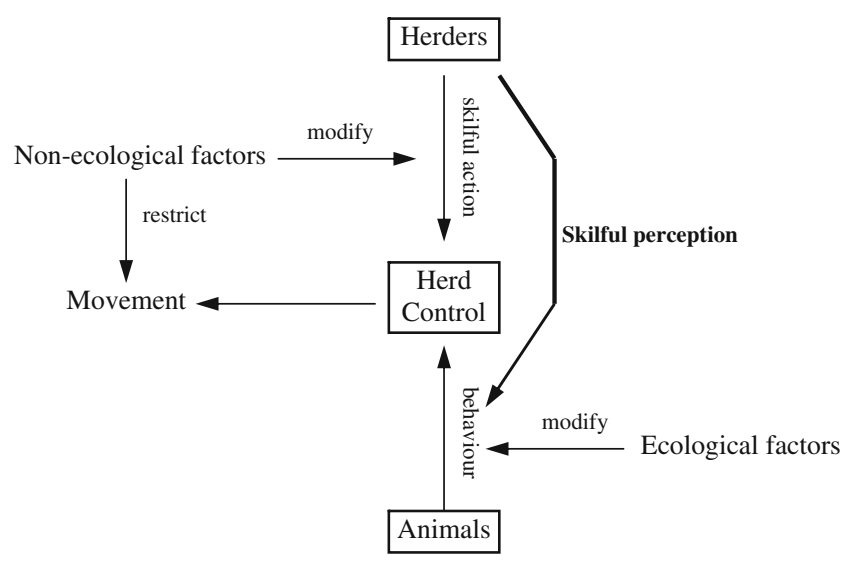

Fig. 3 Proposed model (actor-based) for explaining movement 
behaviour and, on the other, by non-ecological factors that have an impact on the actions of the reindeer herders.

This model seems to have several advantages. Firstly, the analysis of interrelations between the reindeer herders and their animals allows not only the determination of factors that influence reindeer herding movement, but also suggests how these factors work together to produce it. More importantly the model is falsifiable (see Popper 1992), i.e., it can be used to produce testable hypotheses about how certain changes in the ecological and non-ecological environment can influence Komi and Nenets reindeer herding movements. These hypotheses could be empirically tested and the results of this test used to either prove or disprove the model. Finally, this model, which combines a microeconomic as well as cognitive approach to decisionmaking, can work as a useful guide to building more specific and detailed testable explanations. Thus, it could serve as a guide when using optimality theory to analyse nomadic movement. When optimality models are applied separately to the reindeer herd (based, for example, on optimal foraging) and the herders' reaction to it (based on optimizing manpower expenditure), movement can be regarded as the outcome of the interplay between these two optimization strategies. This model should also take into account existing reindeer herding technology and the role of reciprocal learning. If this model is correct, the hypotheses resulting from this approach should describe empirically observable movements better than those resulting from the 'black box' model described previously.

It would, of course, be interesting to know how far, if at all, the principle of herd control could be applied to explain the movement decisions of other reindeer herding nomads as well as nomads in general. We are now entering a completely speculative arena, since, in the absence of substantial comparative data, it is difficult to make sound forecasts. It is probable that herd control is a major issue for all groups of reindeer herding nomads, since reindeer have wild conspecifics and essentially behave as such (unlike cows, sheep, goats, and other domesticated animals herded by other nomads in different regions of the world). This means that no matter how domesticated reindeer become, once included in a herd they move - in order to exploit the resources that are widely distributed in the environment - in a similar way to their wild conspecifics. However, it stands to reason that the degree to which herd control is an issue to the herders depends upon two factors: the level of reindeer domestication (which is largely determined by reindeer ecotype) and the size of a herd. Indeed, the tundra form of reindeer inhabits open areas, is more gregarious than the forest dwelling types, and has developed a more sophisticated social organization (Geist 2003). This could be an advantage for the herders who herd tundra reindeer (Clutton-Brock 1987) and may have been important during the course of the transition from small-scale transport reindeer herding (with herds only in the dozens) to managing large herds of reindeer for food and skins (modern reindeer pastoralism). Consequently, one can imagine that herd control is less of an issue for small-scale reindeer herders (e.g., the Evenki and some Khanti) and it may be that our model cannot be applied to them. On the other hand, herd control is probably an important issue for other large-scale reindeer herders (e.g., Chukchi, Saami, some groups of Yakut, etc), for whom our model is likely to be applicable.

It is even more difficult to judge with certainty how far (if at all) our model can be applied to nomads herding animals other than reindeer. Reindeer are known to be highly atypical amongst domesticated animals due to their low degree of domestication, which they probably acquired relatively recently (Baskin 1970; Krupnik 1993). This suggests that maintaining control over reindeer could be more problematic than over other animals. Nevertheless, as mentioned, there is evidence (e.g., Swidler 1972; Erdenebaatar 1996; Turner 1999; Coppolillo 2000) that southern nomadic pastoralists also have to deal with and react to specific animal behaviour. It was claimed that some aspects of their migratory patterns depended upon this reaction; these included the length of migrations (Erdenebaatar 1996; Turner 1999; Coppolillo 2000) and their direction (Turner 1999). However, we are not aware of any works that have systematically focused on this question. It is also evident, that in the case of southern nomadic-pastoralist systems, the herds more often than not contain several animal species with different behavioural patterns and that there are different aspects of humananimal relations (e.g., milk yield) to which the herders could react when deciding on their movements. However, we believe that treating herders and herds separately and focusing on their interrelations leads to a better understanding of the herders' decision-making, including those decisions related to movement.

\section{Conclusion}

The analysis of reindeer herding technology of the Komi and the Nenets presented in this paper has demonstrated the following:

1. Reindeer pasturing - the central element of the productive cycle in Komi and Nenets reindeer herding - is based on the special relation between the herders and their reindeer. This relation, termed 'herd control', consists of the interplay between reindeer behaviour and the actions of the reindeer herders enabling the latter to maintain herd cohesion by preventing the uncontrolled dispersal of the animals and the avoidance of pastures that could increase the risk of reindeer injury, disease, and mortality or losing track of reindeer. 
2. The nomadic movement of Komi and Nenets herders with their herds can be best understood as the means of maintaining herd control whilst deploying the minimum amount of resources (i.e., human/animal effort and use of equipment) on rounding up the herd, stopping and turning it.

3. Ecological factors influence this movement primarily through their impact on reindeer behaviour and, therefore, on the herders reaction to it. However, we confirm that animal behaviour is influenced by the reciprocal learning process that exists between human and animals within a particular herding (technological) system.

4. Non-ecological factors influence this movement by restricting their direction, timing and range. Their impact, however, is restricted by how feasible it is to maintain herd control using a reasonable deployment of resources.

These aspects were used to compile a model explaining the way in which different factors influence reindeer herding movements. This model treats animals and herders as two separate elements of a nomadic pastoral system and focuses on the relationship between them. Although the possibility of applying this model without modification to explain the movement of other groups of nomads remains speculative, the principles upon which it is based appear to be helpful in understanding nomadic pastoralist movement generally.

Acknowledgements The fieldwork undertaken in the Bol'shezemel'skaya tundra was financed by a joint interdisciplinary research scholarship from the British Natural Environment Research Council (NERC) and the British Economic and Social Research Council (ESRC). The fieldwork in the Yamalo-Nenets Autonomous Okrug was undertaken as part of a joint research project between the Max-Planck Institute for Social Anthropology and the Martin-Luther University Halle-Wittenberg (Halle, Germany) and funded by the Collaborative Research Centre (SFB) 586 of the Deutsche Forschungsgemeinschaft. The writing of this paper was also made possible thanks to a PostDoctoral Research Fellowship funded by the British ESRC.

The authors wish to thank their numerous Russian, Komi and Nenets collaborators: in particular the Shurakov, Yangasov, Alekseevich, Larionov, Filippov, Kanev, and Semyashkin extended families (Komi) and the Salinder, Khudi and Tyseda extended families (Nenets) for their assistance, patience and extraordinary generosity. Finally, we wish to thank our colleagues Tim Bayliss-Smith, Brian Donahoe, Joachim Otto Habeck and Günther Schlee for their suggestions, Eileen Dwyer for her editing contribution and criticisms and Ian Agnew for his cartography skills.

Open Access This article is distributed under the terms of the Creative Commons Attribution Noncommercial License which permits any noncommercial use, distribution, and reproduction in any medium, provided the original author(s) and source are credited.

\section{References}

Adriansen, H. K., and Nielsen, T. T. (2002). Going Where the Grass is Greener: On the Study of Pastoral Mobility in Ferlo, Senegal. Human Ecology 30(2): 215-226.
Babushkin, A. I. (1930). Bol'shezemel'skya Tundra, Obstatotdel, Syktyvkar, Russia.

Barth, F. (1960). The Land Use Patterns of Migratory Tribes of South Persia. Norsk Geografisk Tidsskrift Bind XVII: 1-11.

Barth, F. (1961). Nomads of South Persia, Little, Brown and Company, Boston.

Baskin, L. M. (1970). Severny Olen: Ekologiya i Povedeniye, Nauka, Moscow.

Bates, D. G. (1972). Differential Access to Pasture in a Nomadic Society: The Yörük of Southeastern Turkey. Journal of Asian and African Studies 3(1-2): 48-59. Reprinted in Irons, W. and Dyson-Hudson, N. (eds.) (1972), Perspectives on Nomadism, E. J. Brill, Leiden, NL, pp. 48-59.

Bates, D. G. (1973). Nomads and Farmers: A Study of the Yörük of Southeastern Turkey, Anthropological papers \# 52, Museum of Anthropology, University of Michigan Press, Ann Arbor.

Beach, H. (1990). Comparative systems of reindeer herding. In Galaty, J. G., and Johnson, D. L. (eds.), The World of Pastoralism: Herding Systems in Comparative Perspective, Belhaven Press, London, pp. 255-298.

Burnham, P. (1975). "Regroupment" and Mobile Societies: Two Cameroon Cases. The Journal of African History 16(4): 577594.

Casimir, M. (1992). The ecological determinants of territorial behaviour among mobile herders. In Casimir, M., and Rao, A. (eds.), Mobility and Territoriality: Social and Spatial Boundaries Among Foragers, Fishers, Pastoralists and Peripatetics, Berg, New York, pp. 153-203.

Clutton-Brock, J. (1987). A natural history of domesticated mammals, Cambridge University Press/British Museum (Natural History), Cambridge and London.

Coppolillo, P. B. (2000). The Landscape Ecology of Pastoral Herding: Spatial Analysis of Land Use and Livestock Production in East Africa. Human Ecology 28(4): 527-560.

Cronk, L. (ed.) (2000). Adaptation and Human Behavior: An Anthropological Perspective, Aldine de Gruyter, New York.

De Boer, W. F., and Prins, H. H. (1989). Decisions of Cattle Herdsmen in Burkina Faso and Optimal Foraging Models. Human ecology 17(4): 445-464.

Dwyer, M. J., and Istomin, K. V. (2006). Mobility and Technology: Understanding the Vulnerability of Two Groups of Nomadic Pastoralists to Reindeer Losses. Nomadic Peoples 10(2): 142165.

Dwyer, M. J. and Istomin, K. V. (2008). Komi Reindeer Herding: The Effects of Socialist and Post-Socialist Change on Mobility and Land Use. Polar Research. In Press.

Dyson-Hudson, N. (1972). The Study of Nomads. Journal of Asian and African Studies 7: 2-29.

Dyson-Hudson, R., and Dyson-Hudson, N. (1980). Nomadic Pastoralism. Annual Review of Anthropology 9: 15-61.

Dyson-Hudson, R., and McCabe, J. T. (1985). South Turkana Nomadism: Coping with an Unpredictably Varying Environment, Ethnography Series FL17-001, Human Relations Area Files, HRAFLEX Books, New Haven.

Dyson-Hudson, R., and Smith, E. A. (1978). Human Territoriality: an Ecological Reassessment. American Anthropologist 18(1): 2141.

Elam, Y. (1979). Nomadism in Ankole as a Substitute for Rebellion. Africa 49(2): 147-158.

Erdenebaatar, B. (1996). Socio-economic aspects of the pastoral movement patterns of Mongolian herders. In Humphrey, C., and Sneath, D. (eds.), Culture and Environment in Inner Asia, The White Horse Press, Cambridge, pp. 58-110.

Evans-Pritchard, E. E. (1940). The Nuer, Clarendon Press, Oxford.

Forde, C. D. (1934). Habitat, Economy and Society: a Geographical Introduction to Ethnology, Methuen \& Co. ltd., London. 
Geist, V. (2003). Of reindeer and man, modern and Neanderthal: a creation story founded on a historic perspective on how to conserve wildlife, woodland caribou in particular. Rangifer 14: 57.

Gulliver, P. H. (1975). Nomadic movements: causes and implications. In Monod, T. (ed.), Pastoralism in Tropical Africa, Oxford University Press, Oxford, pp. 369-386.

Habeck, J. O. (2005). What it Means to be a Herdsman: The Practice and Image of Reindeer Husbandry among the Komi of Northern Russia, LIT Verlag, Münster.

Ingold, T. (1986). The Appropriation of Nature: Essays on Human Ecology and Social Relations, Manchester University Press, Manchester.

Ingold, T. (1988). Hunters, Pastoralists and Ranchers, Cambridge University Press, Cambridge.

Ingold, T. (1990). An Anthropologist Looks at Biology. Man 25(2): 208-229.

Ingold, T. (1996). The optimal forager and economic man. In Descola, P., and Palsson, G. (eds.), Nature and Society: Anthropological Perspectives, Routledge, London, pp. 25-44.

Ingold, T. (2000). The Perception of the Environment: Essays on Livelihood, Dwelling and Skill, Routledge, London.

Irons, W. (1974). Nomadism as Political Adaptation: The Case of Yomut Turkmen. American Ethnologist 1(4): 635-658.

Irons, W., and Dyson-Hudson, N. (eds.) (1972). In Perspectives on Nomadism, E. J. Brill, Leiden.

Kercelli, S. V. (1911). Po Bol'shezemel'skoy Tundre s Kkochevnikami, Gubernskya Tipografia, Archangelsk, Russia.

Konstantinov, Y. (2004). Towards a Model of Comparing Transitional Forms in Russian Reindeer herding, MPI für Ethnologische Forschung, Halle (Saale).

Krupnik, I. (1993). Arctic adaptations: native whalers and reindeer herders of Northern Eurasia. University Press of New England, Hannover.

Lattimore, O. (1940). Inner Asian Frontiers of China, American Geographical Association Press, New York.

Little, M. A., and Leslie, P. W. (eds.) (1999). In Turkana Herders of the Dry Savanna: Ecology and Biobehavioral Response of Nomads to an Uncertain Environment, Oxford University Press, Oxford.

Maksimov, S. V. (1984)[1868]. God na severe [One Year in the North]. Severo-Zapadnoye Izdatelstvo, Archangelsk.

McCabe, J. T. (1994). Mobility and land use among African pastoralists: Old conceptual problems and new interpretations. In Fratkin, E., Galvin, K. A., and Roth, E. A. (eds.), African Pastoral Systems: An Integrated Approach, Lynne Rienner Publishers, London, pp. 69-90.

Mulder, M. B., and Sellen, D. W. (1994). Pastoralist decision making: a behavioral ecological perspective. In Fratkin, E., Galvin, K. A., and Roth, E. A. (eds.), African Pastoral Systems: An Integrated Approach, Lynne Rienner Publishers, London, pp. 205-230.
Myers, J. L. (1941). Nomadism. The Journal of the Royal Anthropological Institute of Great Britain and Ireland 71(1/2): 19-42.

Orlove, B. S. (1980). Ecological Anthropology. Annual Review of Anthropology 9: 235-273.

Paine, R. (1972). The herd management of Lapp reindeer pastoralists. In Irons, W., and Dyson-Hudson, N. (eds.), Perspectives on Nomadism, E. J. Brill, Leiden, pp. 76-87.

Paine, R. (1994). Herds of the Tundra: a portrait of Saami reindeer pastoralism, Smithsonian Institute Press, Washington, D.C.

Popper, K. R. (1992). Logic of scientific discovery. Routledge, London.

Robbins, P. (1998). Nomadisation in Rajastan, India: Migration, Institutions and Economy. Human Ecology 26(1): 87-112.

Salzman, P. C. (2003). The Political Ecology of Pastoralism, Westview, Oxford.

Salzman, P. C. (2004). Pastoralists: Equality, Hierarchy and the State, Westview, Oxford.

Schareika, N. (2001). Environmental Knowledge and Pastoral Migration Among the Wodaabe of South-Eastern Niger. Nomadic Peoples 5 (1): $65-87$.

Semple, E. C. (1933). Influences of Geographic Environment, Constable \& Co. Ltd., London.

Sieff, D. F. (1997). Herding Strategies of the Datoga Pastoralists of Tanzania: Is Household Labour a Limiting Factor? Human Ecology 25(4): 519-544.

Skogland, T. (1989). Comparative Social Organization of Wild Reindeer in Relation to Food, Mates and Predator Avoidance. Advances in Ethology 29: 1-74.

Skogland, T. (1991). What are the Effects of Predators on Large Ungulate Populations? OIKOS 61: 401-411.

Smith, E. A. (1983). Anthropological Applications of Optimal Foraging Theory: A Critical Review. Current Anthropology 24: 625-651.

Spooner, B. (1972). The status of nomadism as a cultural phenomenon in the middle east. In Irons, W., and Dyson-Hudson, N. (eds.), Perspectives on Nomadism, E. J. Brill, Leiden, pp. 122-131.

Stenning, D. J. (1958). Household viability among pastoral Fulani. In Goody, J. (ed.), The Developmental Cycle in Domestic Groups, Cambridge University Press, Cambridge, pp. 91-119.

Stenning, D. J. (1959). Savanna Nomads: A Study of the Wodaabe Pastoral Fulani of Western Bornu Province, Oxford University Press, London.

Swidler, W. W. (1972). Some demographic factors regulating the formation of folks and camps among the Brahui of Baluchistan. In Irons, W., and Dyson-Hudson, N. (eds.), Perspectives on Nomadism, E. J. Brill, Leiden, pp. 69-75.

Turner, M. D. (1999). Labour Process and the Environment: the Effects of Labour Availability and Compensation on the Quality of Herding in the Sahel. Human Ecology 27(2): 267-296. 